\title{
Appreciation
}

\section{Dr Meliyanthi Megasuriya Gunatillaka}

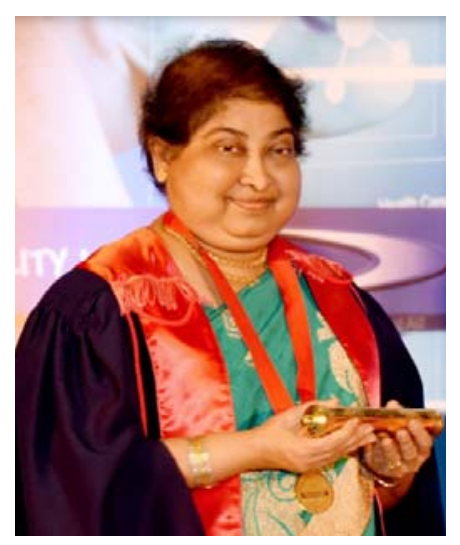

Creation of a medical specialist, who would serve the country faithfully, is no accident. It is the cumulative effect of life-long study, discipline and commitment. When the said specialty has sparse number of members, the responsibility and the worth of each member rises dramatically. In such a scenario, the untimely demise of a senior member, Dr. Meliyanthi Gunatillaka, has proven to be a definite blow, a great sadness and loss to the fraternity of Chemical Pathologists in the country.

Dr Meliyanthi Megasuriya Gunatillaka, MBBS, D.Path, MD (Chem. Path) obtained her primary and secondary education from Holy Family Convent, Kurunegela. Having obtained her MBBS degree from the Faculty of Medicine, University of Colombo in 1985 she proceeded to follow the Postgraduate training programme in Pathology offered by the Postgraduate Institute of Medicine, University of Colombo. She trained as a registrar in Pathology attached to the Departments of Pathology, Teaching Hospital, Karapitiya and National Hospital of Sri Lanka and obtained the MD (Pathology) Chemical Pathology in 1997.

She had her post MD overseas training at the Department of Chemical Pathology, Southampton General Hospital, UK and took up her first post as a Consultant Chemical Pathologist at the Endocrine and Radioisotopic Unit at the Department of Biochemistry, Medical Research Institute (MRI), Colombo in December 1999. She was appointed as the Head, Department of Biochemistry at MRI in January 2001 and served the Institution until October 2013.

In addition to conducting the routine Chemical Pathology services at the Department of Biochemistry, which included general biochemical, hormone and tumour marker assays, she organized and supervised the National External Quality Assessment (NEQAS) programme for tests in General Biochemistry for the state sector hospital laboratories in Sri Lanka, which were 65 in number. At a time when the number of Chemical Pathologists was scarce, she assisted the peripheral laboratories in the state sector in the establishment of general and specialized biochemical testing by offering training for the technical staff at the Department of Biochemistry at MRI. Further she assisted the Ministry of Health in evaluating medical devices, prior to registration at the Cosmetics, Drugs and Devices Authority and the State Pharmaceuticals Cooperation in evaluating chemicals used for biochemical tests. 
She took up post as the Consultant Chemical Pathologist at the Department of Biochemistry, National Hospital Sri Lanka in October 2013 and worked towards extending, strengthening and further improving the quality of the Chemical Pathology services offered by the National Hospital.

She was a trainer for postgraduate trainees for the Diploma in Pathology, Diploma in Chemical Pathology and MD in Chemical Pathology and was a strict disciplinarian who demanded the best from her students. She guided them well in acquiring laboratory skills, with an emphasis on assuring quality. She had contributed as an examiner/chief examiner for the MD in Chemical Pathology and Diploma in Chemical Pathology examinations and an examiner for Diploma in Pathology and Selection Examination in Pathology a number of times.

She served as a member of the Board of study in Pathology at the Postgraduate Institute of Medicine University of Colombo, from 2003 to 2006 and then again from January 2014. She contributed actively for revising the curriculum in Postgraduate training in Chemical Pathology during both her tenures as a member of the Board of Study.

She was a member of the Advisory Board for the training of Medical Laboratory Technologists and the Chief Examiner in Chemical Pathology component of the final and first year examinations at the Schools of
Medical Laboratory Technology at Colombo, Kalutara and Peradeniya a number of times.

She had a keen interest in accreditation of medical laboratories which she thought was an essential step in improving the standards of laboratory testing both in the private and state sector. Her enthusiasm in accreditation paved the way for her to become a member of the Technical Advisory Committee of the Sri Lanka Accreditation Board for conformity assessment (SLAB). In addition she served the SLAB, as a technical assessor in Chemical Pathology and a technical expert for Preassessments.

She worked tirelessly towards the development of Chemical Pathology as a profession which led to the founding of the College of Chemical Pathologists of Sri Lanka in October 2015, for which she was unanimously appointed as the founder President. The College had its inaugural sessions in March 2016, under the auspices of the Asia Pacific Federation of Clinical Biochemistry and the International Federation of Clinical Chemistry, the international stalwarts in Clinical Chemistry, which marked a new era for the Chemical Pathology in Sri Lanka. Though she bid us farewell shortly thereafter, the legacy she had left behind would thrive under the retinue of Chemical Pathologists she had contributed to foster.

We salute her for all she did throughout her career to create a better day for the field of Chemical Pathology in Sri Lanka. May she attain Nibbana!

Dr Deepani Siriwardhana Faculty of Medicine University of Ruhuna Sri Lanka 